Chronic Obstructive Pulmonary Diseases: Journal of the COPD Foundation

\author{
Abstract Presentations
}

\title{
COPD10: Birmingham,United Kingdom, July 2016
}

\author{
Robert A. Stockley, MD ${ }^{1}$
}

Citation: Stockley RA. Abstract presentations: COPD10, Birmingham, United Kingdom, 2016. Chronic Obstr Pulm Dis. 2017;4(3):225246. doi: https://doi.org/10.15326/jcopdf.4.3.2017.0137

1 Queen Elizabeth Hospital, Birmingham, United Kingdom

\section{Address correspondence to:}

Robert A. Stockley, MD

Email: Rob.stockley@uhb.nhs.uk

Phone: +441213713886

\section{Introduction}

The 10th international, multidisciplinary meeting dedicated to chronic obstructive pulmonary disease (COPD), "COPD10," was held in Birmingham, United Kingdom in 2016. This conference series continues to attract attendance from key opinion leaders while also introducing emerging leaders from research, clinical practice and allied health care disciplines.

This year we introduced presentations from "Rising Stars," young investigators who were all nominated for this distinction by their senior colleagues. Topics presented in these sessions were wide-ranging with Liz Sapey, PhD, (United Kingdom) presenting her work on "Abnormal Neutrophil Migration in COPD," Miguel Divo, MD, (United States) speaking on "COPDrelated Comorbidities" and Jennifer Quint, MD, (United Kingdom) presenting work on "Electronic Health Records: The Missing Link in Respiratory Research.” A panel discussion following the presentations could not distinguish the best among the speakers who all gave fabulous insight into their particular area of interest and certainly gave delegates plenty to think about. So, all 3 deservedly shared the "Rising Star" award. A summary of their work accompanies this feature. Future conferences will include more presentations from a wealth of young investigators who will play a major role in future research and advances in the field of COPD.

The conference's Plenary sessions included a period of discussion and debate facilitated by science writer and broadcaster Vivienne Parry with topics including, "Early Disease," "Models of Care," "Pathobiology of Inactivity" and "Future Horizons in COPD." There were 12 simultaneous sessions within the established tracks of clinical science, basic science and care delivery. Speakers presented recent advances and current thinking regarding small airways disease, early identification, cancer and COPD, exacerbations, accelerated lung aging in COPD, inhalers and medicine adherence, and bronchiectasis overlap.

The fourth "Tim Griffiths Memorial Lecture" was delivered by Rachael Evans, MD, (United Kingdom) on "Socio-biology of Inactivity."

Meet the Experts sessions were held each morning and were well attended as usual. There were also dedicated sessions for allied health care professionals to network and discuss topics from the previous day.

The conference saw another 2 very deserving individuals inducted into the "COPD Hall of Fame,": Peter Calverley, MD and Dirkje Postma, MD. They have both made an outstanding contribution to the field of COPD.

A total of 45 submitted abstracts were presented in poster format at the event and the accompanying abstracts are those selected by the COPD 10 Organizing Committee for publication. Facilitated discussion led by Christine Jenkins, MD, Sonia Buist, MD, Charlotte Bolton, $\mathrm{MD}$ and Brendan Cooper, $\mathrm{PhD}$, proceeded a panel decision to award a prize for the best poster to Anne Knowles, BSc, from the Lothian Community 


\section{Professor Peter Calverley}

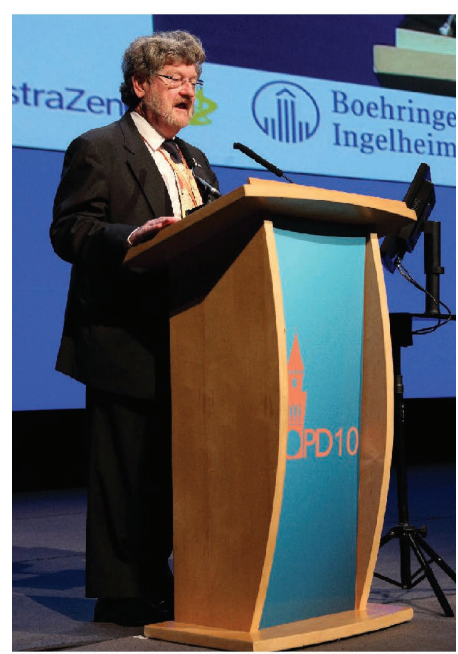

Professor Calverley was recognized for his extensive publications on COPD and clinical trials and his major contribution to the Department of Health Reference Group that formulated the Clinical Strategy for COPD in England.

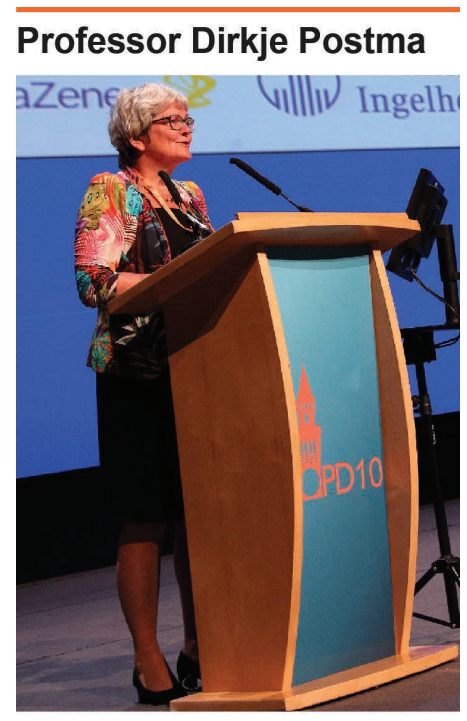

Professor Postma was recognized for her major contributions to our understanding of the risk factors, natural history and management of COPD and for creating and nurturing a multidisciplinary group of

investigators working at the cutting edge of COPD research.
Pulmonary Rehabilitation Service and work presented by Georgia Walton, BSc, Diana Crossley, MD, and Stanley Pupyshev, MD, was highly commended.

The next meeting in the United States of this conference series is COPD10usa in Chicago, Illinois on July 2829, 2017. We are already making plans for COPD11, to be held in Birmingham, United Kingdom, June 20-21, 2018 where we hope to deliver the next update on progress and challenges of COPD.

From a personal point of view, I would like to thank all of our sponsors who provided non-commercial input to the educational program and continue to support this biennial conference which continues to be held in very high regard. Our organizers, Jackie Hutchinson and Executive Business Support, and our conference manager, Anita Pye, all worked tirelessly to make the event a continued success. We are all looking forward to COPD11 in 2018.

NOTE: The following abstracts have NOT been edited but are presented here in their original format, as presented by the author at COPD 10, Birmingham, United Kingdom, 2016.

\section{Abstracts Presented by Rising Stars}

\section{A New Look Into COPD- Related Comorbidities}

Miguel Divo

Brigham and Women's Hospital's Pulmonary and Critical Care Division, Boston, Massachusetts

Life expectancy has augmented at a rapid pace largely due to improvements in the treatment of communicable diseases resulting in an epidemiologic shift toward increased prevalence in non-communicable diseases. ${ }^{1}$ As age advances, individuals are likely to have more than one co-occurring chronic condition, therefore the challenge for healthcare is not just having longer lives but how to be healthier during those extra years. Healthcare's traditional approach using different clinical practice guidelines (CPG) does not consider multi-morbidity in their recommendations, and if we follow CPG recommendations for each co-occurring disease in a typical elderly patient it will results in the prescription of 12 different medications with increased potential to develop adverse interactions and increased costs. $^{2}$

COPD is a prevalent disease worldwide and patients diagnosed with this condition suffer from a high proportion of comorbid conditions. ${ }^{4-7}$ More importantly, two-thirds of individuals suffering from COPD die of non-pulmonary causes and this fact could in part explain why despite having effective bronchodilator therapies, such treatments have small impact in reducing all-cause mortality. 8,9

In 2012, our group described the presence of 79 different comorbidities in the BODE COPD cohort and showed that only 12 comorbidities conferred an increased risk of death when co-occurring with COPD ${ }^{5}$ and where represented in the form of an orbital graph known as the "Comorbidome". However, the true clinical significance of the other 67 comorbidities may not be adequately assessed by standard regression analysis.

We propose that one approach to understand disease interactions is the use of Network science: Network science has emerged as a field focused on the understanding of complex systems by mapping the interconnectivity of such data as persons, proteins, mobile phones or diseases. We are so much trained to look at observations as independent entities, to be analyzed through aggregation that we have lost sight that 
many datasets are actually rich in connections between individual data worthy of exploration points. Networks graphics are composed of individual components called nodes and a grid of interconnecting edges representing some type of association between nodes. In addition to the graphic, The Network's structure will help to identify highly connected nodes and specific clusters of nodes with potential applicability: Common biologic pathways, targets for intervention or screening.

Using this approach, in 2015 we described the "COPD Comorbidities Network"13 and demonstrated that: (1) Comorbidities are not exclusive of patients with COPD however the prevalence and number of simultaneous comorbidities are higher in COPD; (2) Diseases are interlinked beyond simple coincidence, and aggregate forming clusters with meaningful syndromic associations (metabolic syndrome, behavioral/ psychiatric module, among others), that are hypothesis generating; and (3) The COPD Comorbidity Network has group of highly connected comorbidities (hubs) suggesting an influential or intermediary role. In fact, 23 comorbidities out of 79 hold $72 \%$ of the Network's links and interestingly many of those comorbidities are known to influence important outcomes as described in previous studies. ${ }^{14,15,16}$ An example of the network is shown in the figure.

\section{References}

1. Divo, M. J., Martinez, C. H. \& Mannino, D. M. Ageing and the epidemiology of multimorbidity. Eur. Respir. J. erj00598-2014 (2014). 2. JAMA-2005-Boyd-716-24 comorbidities management. 1-9 (2005). 3. MD, P. R. L. et al. Global and regional mortality from 235 causes of death for 20 age groups in 1990 and 2010: a systematic analysis for the Global Burden of Disease Study 2010. Lancet 380, 2095-2128 (2012). 4. Martinez, C. H., Mannino, D. M., Divo, M. J. \& others. Defining COPDrelated comorbidities, 2004-2014. Chronic Obstr. Pulm. Dis. J. COPD Found. 1, 51-63 (2014).

5. Divo, M. et al. Comorbidities and risk of mortality in patients with chronic obstructive pulmonary disease. Am. J. Respir. Crit. Care Med. 186, 155-161 (2012).

6. Schnell, K. et al. The prevalence of clinically-relevant comorbid conditions in patients with physician-diagnosed COPD: a cross-sectional study using data from NHANES 1999--2008. BMC Pulm. Med. 12, 26 (2012).

7. Mapel, D. W. et al. Health care utilization in chronic obstructive pulmonary disease. A case-control study in a health maintenance organization. Arch. Intern. Med. 160, 2653-2658 (2000).

8. Calverley, P. M. A. et al. Salmeterol and Fluticasone Propionate and Survival in Chronic Obstructive Pulmonary Disease. N. Engl. J. Med. 356, 775-789 (2007).

9. McGarvey, L. P., John, M., Anderson, J. a, Zvarich, M. \& Wise, R. A. Ascertainment of cause-specific mortality in COPD: operations of the TORCH Clinical Endpoint Committee. Thorax 62, 411-415 (2007).

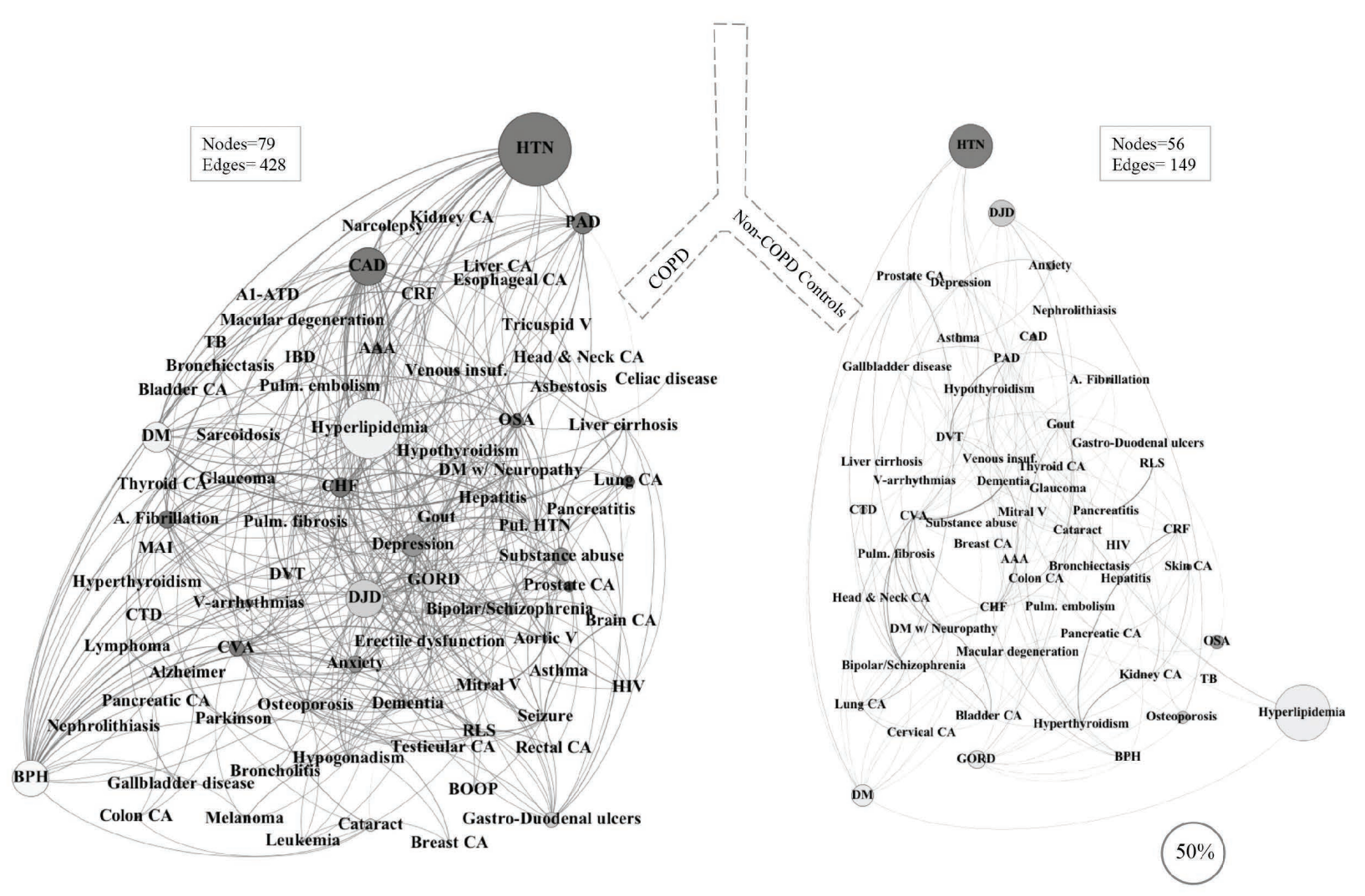

For personal use only. Permission required for all other uses. 
10. Fabbri, L. M., Beghé, B. \& Agustí, A. COPD and the Solar System. Am. J. Respir. Crit. Care Med. 186, 117-119 (2012).

11. Burgel, P.-R. R. et al. Clinical COPD phenotypes: a novel approach using principal component and cluster analyses. Eur. Respir. J. 36, 531-539 (2010).

12. Garcia-Aymerich, J. et al. Identification and prospective validation of clinically relevant chronic obstructive pulmonary disease (COPD) subtypes. Thorax 66, 430-437 (2011).

13. Divo, M. J. et al. Chronic obstructive pulmonary disease comorbidities network. Eur. Respir. J. ERJ-01716-2014 (2015).

14. Mancini, G. B. J. et al. Reduction of Morbidity and Mortality by Statins, Angiotensin-Converting Enzyme Inhibitors, and Angiotensin Receptor Blockers in Patients With Chronic Obstructive Pulmonary Disease. J. Am. Coll. Cardiol. 47, 2554-2560 (2006).

15. Putcha, N. et al. Impact of co-morbidities on self-rated health in selfreported COPD: an analysis of NHANES 2001-2008. COPD J. Chronic Obstr. Pulm. Dis. 10, 324-332 (2013).

16. Etminan, M., Jafari, S., Carleton, B. \& FitzGerald, J. Beta-blocker use and COPD mortality: a systematic review and meta-analysis. BMC Pulm. Med. 12, 48 (2012).

\section{Electronic Health Records: The Missing Link in Respiratory Research}

Jennifer Quint

Imperial College of London, United Kingdom

\section{Background:}

Routinely collected electronic health records provide a unique and underutilised resource from which multiple aspects of disease can be studied. The availability of electronic health records for research has dramatically increased in recent years with new linkages and more detailed datasets becoming available for researchers. However, observational research is often considered substandard to randomised controlled trials and although randomised controlled trials have long been accepted to be the gold standard for assessing the effectiveness of medical interventions, and development of guidelines, they are expensive to conduct and have been criticised for testing treatments in patient populations and within contexts which are sometimes very different to real life. Additionally, as large RCTs are expensive in terms of time and money, many fewer trials are conducted than is ideal.

As patient populations with chronic respiratory diseases such as COPD become more complex, the studies used to generate clinical evidence must reflect this. The combination of demands for evidence and increased data availability means we now need rigorous methodology to translate complex data into evidence.
As real-world evidence emerges in this environment, policy-deciding bodies such as the National Institute of Health and Care Excellence (NICE) will increasingly determine treatment effectiveness outside the randomised testing environment and use this evidence for treatment guidelines.

\section{Methods:}

Using examples across a range of respiratory diseases (COPD, bronchiectasis, pneumonia, asthma), this talk will illustrate through use of a number of databases (e.g. Clinical practice research datalink, hospital episode statistics and the myocardial infarction national audit project) why using electronic health records to study respiratory disease is increasingly important.

\section{Results:}

Challenges, pitfalls and limitations will be highlighted ${ }^{1,2}$ along with results from studies that have produced meaningful results for clinical practice. ${ }^{3-11}$ Finally, novel clinical trial recruitment strategies, and prognostic model development will be discussed along with newer epidemiological methodologies for dealing with increasingly complex data linkages.

\section{Discussion:}

Electronic health records underpin the future of the health service and are an invaluable resource both for clinical practice and medical research. Strengths include their massive size and the ability to collect data on real clinical practice in almost real time. The potential for electronic health records to help clinicians and patients make better decisions is yet to be fully realised.

\section{References}

1. Quint, et al. BMJ Open, 4(7), e005540. doi:10.1136/bmjopen-2014005540

2. Millett, et al. J Clin Epidemiol. doi:10.1016/j.jclinepi.2016.01.005

3. Windsor, et al. International Journal of COPD, 11, 217-225.

doi:10.2147/COPD.S95775

4. Barakat, et al. International Journal of COPD, 10, 2067-2077.

doi:10.2147/COPD.S88759

5. Rothnie, et al. HEART, 101(14), 1103-U113. doi:10.1136/

heartjnl-2014-307251

6. Müllerová, et al. BMJOpen, 4(12), e006171. doi:10.1136/

bmjopen-2014-006171

7. Quint, et al. BMJ, 347, f6650. Retrieved from http://www.ncbi.nlm.

nih.gov/pubmed/24270505

8. Quint, et al. ERJ47(1), 186-193. doi:10.1183/13993003.01033-2015

9. Iwagami, et al. BMC PULMONARY MEDICINE, 16, 8 pages.

doi:10.1186/s12890-016-0177-5 
10. Millett, et al. BMJOpen, 5(12), e008737. doi:10.1136/ bmjopen-2015-008737

11. Millett, et al. PLoSOne, 8(9), e75131. doi:10.1371/journal. pone.0075131

\section{Abnormal Neutrophil Migration is a Feature of Early COPD, Present Across Disease Phenotypes, Causally Related to Increased Phosphoinositide-3-Kinase Signaling and Associated With Increased Inflammation}

Elizabeth Sapey

University of Birmingham and Queen Elizabeth Hospital, Birmingham, United Kingdom

\section{Introduction:}

There may be multiple genetic susceptibility factors leading to the condition we recognise as COPD, but identifying and developing treatments for everyone presents a major therapeutic challenge. Identification of a central pathway may therefore provide a viable alternative.

COPD is heterogeneous, but all clinical phenotypes have airway neutrophilia. Neutrophil-derived reagents are strongly implicated in tissue injury and neutrophil numbers and products correlate with disease pathology, severity and decline. Aberrant neutrophil functions may contribute to disease development and progression in COPD and while genetic drivers may differ between individuals, dysfunctional neutrophils may represent a common hub in a hub and spoke model of disease pathogenesis.

Neutrophil functions that might contribute to disease pathogenesis include chemotaxis, phagocytosis, extracellular ROS release and NET production and we have assessed each in COPD patients to identify potential targets for immunomodulation.

\section{Methods:}

Blood neutrophils were isolated from COPD patients ( $\mathrm{n}=105)$ ( \pm emphysema, \pm chronic bronchitis and with frequent ( $\geq 2 /$ year) or non-frequent ( $<2 /$ year) exacerbations) and patients with chronic severe asthma $(\mathrm{n}=10)$, Bronchiectasis $(\mathrm{n}=10)$, Alpha-1-Antitrypsin deficiency $(n=50)$ (all matched for $F E V_{1}$ ) and $n=75$ smoking (HS) and never-smoking (HNS) controls. Neutrophils were also isolated from bronchoalveolar lavage(BAL) samples.

Neutrophil migration was assessed following incubation with Class 1 isoform selective PI3K, Erk, P38 kinase and SHIP inhibitors or carrier controls. Opsonised and unopsonised phagocytosis of nontypable haemophilus influenzae, strep. pneumo, e.coli and staph. aureus and NETs release were assessed. PI3K and downstream pAKT was determined by western blotting. Surface expression of receptors associated with adherence and degranulation were assessed using flow cytometry.

\section{Results:}

COPD neutrophils initiated migration faster than other groups including healthy controls (time to migrate 5um; COPD 48s (SD 13s) Vs. HS 68s (SD 19s), p=0.001) with increased random movement (chemokinesis) but reduced accuracy (chemotaxis) towards a series of inflammatory stimuli ( $\mathrm{p}=0.01$ or less for all). This was seen across all COPD phenotypes, in early to severe disease but not in other inflammatory lung conditions. The normal reduction of migratory accuracy seen with increasing age was lost, with COPD neutrophil migration impaired at every age. Other functions, including phagocyotosis and NET production were preserved. These cellular features were stable in the same individuals across time, and also in transmigrated BAL cells.

COPD neutrophils expressed more surface markers associated with degranulation (such as CD63) and systemically these patients had increased markers

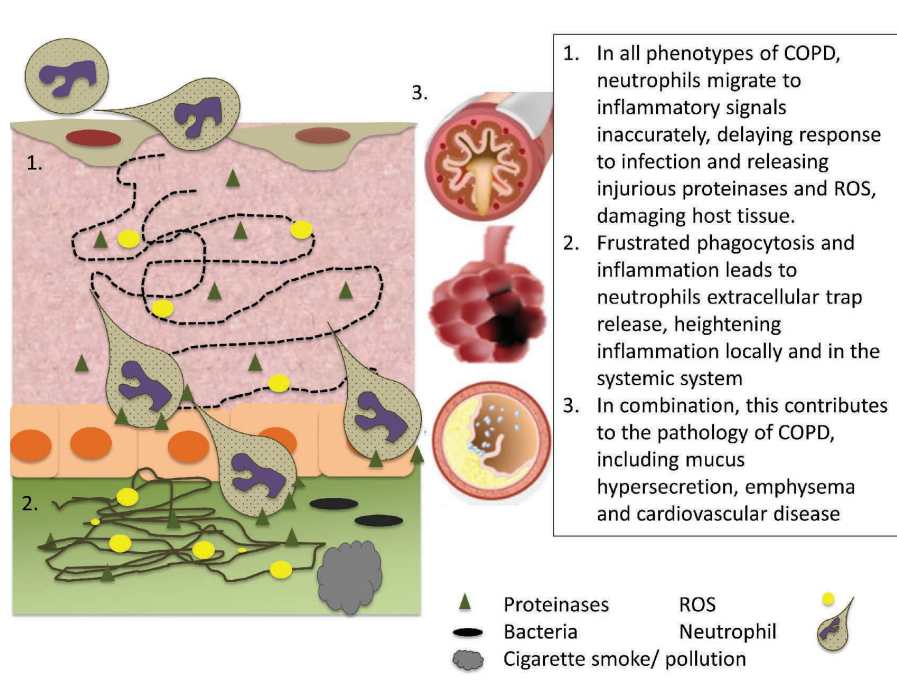


of neutrophil elastase activity (including Aa360VAL) compared to HS.

Inaccurate migration was causally associated with increased PI3K activity; COPD neutrophils demonstrated constitutive PI3K and downstream AKT activation compared with HS neutrophils. PI3K blocking strategies, specifically inhibition of PI3K gamma and delta isoforms, restored neutrophil migratory accuracy without impeding phagocytosis. Other compounds tested were unable to normalise cellular functions.

\section{Conclusion:}

Neutrophils from patients with COPD display increased random migration compared with inflammatory and smoking controls, but are less accurate. This is seen across disease phenotypes and stages of severity and could contribute to the increased tissue damage and reduced bacterial clearance seen in COPD. Targeting neutrophils via PI3K may provide a novel therapeutic target for disease modification across all phenotypes of disease.

\section{COPD10 2016 Abstracts}

\section{Endurance Versus Resisted Exercise on Chronic Obstructive Pulmonary Disease in Elderly Patients}

Walid Kamal M. A. ${ }^{1,2}$ \& Gopal Nambi S. ${ }^{1}$

${ }^{1}$ Department of Physical Therapy and Health Rehabilitation, College of Applied Medical Sciences, Prince Sattam Bin Abdul Aziz University, Alkharj, Saudi Arabia. ${ }^{2}$ Department of Physical Therapy, Kasr Al-Aini Hospital, Cairo University, Egypt.

\section{Background:}

Many studies have evaluated the effect of endurance exercise on COPD but there is limited data on the effectuality of resistance exercise on COPD. This study has compared the impacts of endurance exercise to the impacts of resisted exercise on COPD in elderly patients.

Patients and methodology: Between December 2015 and April 2016, forty obese elderly patients with moderate COPD with age of 60-70 years were selected for this study. Their body mass index (BMI) ranged from 30 to $\geq 40 \mathrm{~kg} / \mathrm{m}^{2}$. They were randomly classified into two groups, each group comprised of 20 patients, group A received a program of endurance exercise (EE 3 times/ week for 12 weeks) and group B received a program of resisted exercise (RE 3 times/week for 12 weeks). The pulmonary function changes (FVC, FEV $1, F_{1} V_{1} / F V C \%$, FEF 25-75\% and MVV) have been measured at the commencement and the end of the study.

\section{Results:}

Showed that Endurance exercise had greater improvement in FVC, FEV1, FEV1/FVC\%, FEF25-75\% and MVV were respectively $(+0.13,+0.22,+4.6,+0.13$ and +4.82) when compared to the resisted exercise group were respectively $(+0.1,+0.19,+4.2,+0.09$ and $+3.8)$.

\section{Conclusion:}

It was concluded that both groups have similar effects on pulmonary function but a program of endurance exercise showed greater improvement than a program of resisted exercise in elderly patients with COPD in a short term (up to twelve weeks). 


\section{Pulmonary Function, Health Status and Other Clinical Measures as Predictors of COPD Exacerbations}

\author{
Mehmet Polatli ${ }^{1}$ Fatma Varol ${ }^{2}$ Zeynep Gunes ${ }^{2}$ \\ ${ }^{1}$ Adnan Menderes University, School of Medicine \\ Chest Disease Department, AYDIN, TURKEY ${ }^{2}$ Adnan \\ Menderes University, Graduate School of Health \\ Sciences, Department of Internal Medicine Nursing, \\ Aydin, Turkey
}

\section{Aims:}

Exacerbations of chronic obstructive pulmonary disease (COPD) are of major importance because of their effects on considerable physiologic deterioration and increased inflammation which leads to decrease in health-related quality of life, increase in morbidity and mortality. In general, exacerbations become more frequent with increasing disease severity but some patients are prone to frequent exacerbations. In this study, we aimed to evaluate the clinical measures as predictors of COPD exacerbations.

\section{Methods:}

Individuals with COPD were recruited from outpatient clinic in a University hospital. Information on age, gender, body mass index (BMI), smoking status, St. Georges Respiratory Questionnaire (SGRQ), mMRC, COPD Assessment Test (CAT), comorbidities, and exacerbations in the past year was collected and a spirometry was performed.

\section{Results:}

We enrolled 319 COPD patients (283 men) with a mean age of $64.51 \pm 10.05$ years and mean percent predicted $\mathrm{FEV}_{1}$ of $63.49 \pm 21.66$. According to spirometric severity, the rate of cachexia was higher in GOLD III and IV. The exacerbation frequency was significantly correlated with disease duration, pulmonary function, SGRQ, CAT, mMRC but not with smoking history and BMI (Table 1). The regular polyclinic control of patients was higher in more severe groups compared to mild patients. The medical treatment adherence was also lower in mild group. Although the comorbidities influence SGRQ and $C A T$, the exacerbation frequency was independent from comorbidities.

\section{Conclusions:}

Because of the clinical measures such as disease duration, spirometry, CAT, mMRC and the SGRQ are independent predictors COPD exacerbations, multidimensional scales for measuring COPD severity should be taken into consideration. The education about the raising awareness of COPD may influence the adherence to treatment and changing life styles in mild patients.

Table 1. The exacerbation frequency correlation with disease duration, pulmonary function, GOLD spirometric classification, SGRQ, CAT and mMRC, smoking history and BMI.

Disease duration

Postbronchodilator FEV1 \%

Postrbronchodilator FEV1/FVC

GOLD Spirometric Classification

St. Georges Respiratory Questionnaire

(SGRQ)

Symptoms

Activity

Impact

Total

CAT

SmMRC

BMI

$\begin{array}{ll}R \text { values } & p \text { values } \\ 0.168 & 0.003 \\ -0,394 & <0.001 \\ -0,293 & <0.001 \\ 0,377 & <0.001 \\ & \\ 0,634 & <0.001 \\ 0,493 & <0.001 \\ 0,527 & <0.001 \\ 0,576 & <0.001 \\ & \\ 0,471 & <0.001 \\ 0,466 & <0.001 \\ 0,102 & 0.069 \\ -0.023 & 0.689\end{array}$

\section{A Comparison of the ADO, BODE and DOSE Scores for Predicting Respiratory Hospitalisations in a Primary Care COPD Cohort}

Andy Dickens, Rachel Jordan, Alexandra Enocson, David Fitzmaurice, Alice Sitch, Peymane Adab

University of Birmingham, Birmingham, UK

\section{Introduction:}

Several multidimensional prognostic indices (PI) for COPD have been developed, mostly based on patients with moderate/severe COPD. The Birmingham COPD Cohort study will examine the validity of these indices in a primary care COPD population.

\section{Aims \& objectives:}

Use preliminary data to determine the predictive ability of selected PIs in relation to self-reported respiratory hospitalisations.

\section{Methods:}

Baseline data from 663 participants of the Birmingham COPD cohort study were used to calculate scores of 3 PIs (ADO, BODE, DOSE). The c statistic was derived to compare their discrimination in predicting risk of respiratory hospitalisation at 1 and 2 years. 
Results: According to c statistic estimates, ADO was better at predicting 1-year respiratory hospitalisations ( $\mathrm{C}=0.81 ; 95 \%$ CI 0.75 to 0.88$)$ than DOSE ( $\mathrm{C}=0.73$, $95 \%$ CI 0.65 to 0.81$)$ and BODE ( $=0.75$, 95\% CI 0.67 to 0.83 ). The same pattern was observed for 2-year respiratory hospitalisations. All scores were better at predicting hospitalisations than their component parts.

\section{Conclusions:}

The data suggest that ADO could be a useful tool for identifying those at higher risk of respiratory hospitalisations. The analyses will be repeated on the complete sample once data is available.

\section{Does Depression on Discharge Predict Readmission in COPD Patients Admitted With Acute Exacerbation?}

V. Padmanaban, E. Luke, R Musgrave, A. Campisi, C. Bloom, S. Elkin

Imperial College Healthcare NHS Trust, St Mary's Hospital, Praed Street, London, W2 1NY

\section{Background:}

Psychological co morbidities are common in Chronic Obstructive Pulmonary Diseases (COPD). Previous studies have shown association with increased mortality, exacerbation rates, increased readmission, length of hospital stay, and decreased quality of life ${ }^{1}$. We wished to investigate if hospital re-attendances could be higher in patients with higher depression scores in Hospital Anxiety and Depression (HAD) scale.

\section{Methods:}

Between October 2013 and April 2015, we collected HAD score on discharge from 101 COPD patients admitted with acute exacerbation. We also collected data on hospital readmission, Accident \& Emergency Department (A\&E) attendances and community respiratory team contacts in these patients up to 1 year from discharge.

\section{Findings:}

We found Depressed COPD patient on discharge were more likely to attend A\&E for breathing related problems than the non-depressed $(p<0.05)$ over 1 year follow up post discharge. The odds of attending A\&E within 1 year post discharge were 3.2 times higher in the depressed than in not depressed by HAD score (OR=3.24, 95\% CI 1.11-9.47, p=0.02). However they did not have higher odds of readmission.

\section{Conclusion:}

There is an increased risk of a high depression score and increase in A\&E visits related to breathing, unfortunately we didn't see any association with readmission rates in this cohort. Screening COPD patients for psychological disorders on discharge is important to identify and enable timely intervention for these high risk patients, we propose that assessment of mood disorders such as anxiety and depression, should be included as part of the routine care for all COPD patients, admitted with an exacerbation. Further studies with increased numbers are needed to asses if earlier intervention reduces healthcare utilisation.

\section{References:}

1. Atlantis et al. Bidirectional associations between clinically relevant depression or anxiety and COPD: a systematic review and meta-analysis. Chest. 2013;144(3): 766-777.

\section{Can Urinary Biomarkers Be Used to Improve Prediction of COPD Exacerbations?}

Gita Parekh ${ }^{1}$ Paul J. Davis ${ }^{1}$ Bruce E. Miller ${ }^{2}$ Ruth TalSinger ${ }^{2}$

${ }^{1}$ Mologic, Ltd, Thurleigh, United Kingdom ${ }^{2}$ Respiratory Therapy Area Unit, GSK R\&D, King of Prussia, PA, USA

\section{Introduction:}

Repeated exacerbations of COPD are associated with a rapid decline in lung function. Currently the best predictor of exacerbation is the patient's exacerbation history.

\section{Methods:}

Baseline urine from 98 COPD subjects was evaluated with 25 urinary biomarkers. Forty-eight of the subjects had infrequent exacerbations. Thirty-three participants were frequent exacerbators (2-7 exacerbations/year). 16 subjects who had $\leq 1$ exacerbation prior to recruitment experienced 2-8 exacerbations in year one. One subject had 3 exacerbations prior to recruitment but experienced 
no exacerbations in year one.

\section{Results:}

A combination of 10 biomarkers - (Composite matrix metalloproteinases (MMP) activity, tissue inhibitors of metalloproteinases-1 (TIMP-1), desmosine, fibrinogen, interleukin 6 (IL-6), interleukin 8 (IL-8), interleukin 1 beta (IL-1ß) and alpha 1 antitrypsin (A1AT)) with post-bronchodilator $\mathrm{FEV}_{1}$ \%predicted and SGRQ (two non-biomarker parameters) was predictive. This panel differentiated the infrequent and frequent groups (specificity, 91.5\%; sensitivity, 90.6\%; AUC = 0.92). The model correctly predicted 13 of the 16 subjects who converted from infrequent to frequent exacerbation, with a sensitivity of $81.3 \%$ and the one subject from frequent to infrequent state. These 13 subjects would have been missed on the basis of patient exacerbation history but were correctly identified by means of these biomarkers.

\section{Conclusions:}

For the first time, urinary biomarkers have been shown to predict frequency of exacerbations and if confirmed in larger cohorts could be used to complement existing methods for monitoring disease severity and management of COPD exacerbations.

The ECLIPSE Study (NCT00292552, GSK Study SCO 104960) was sponsored by GSK

\section{Oral Health in COPD and Alpha-1 Antitrypsin Deficiency (AATD)}

S. Hobbins ${ }^{1}$ R.A. Stockley ${ }^{2}$

${ }^{1}$ Institute of Inflammation and Ageing, University of Birmingham, UK ${ }^{2}$ Lung Investigation Unit, University Hospitals Birmingham NHS Foundation Trust, UK

\section{Introduction:}

Many of the pathophysiological factors for dental disease are also common to COPD including inflammation, poor nutrition and smoking. Oral health interacts with other co-factors including environmental pollutants, infection, allergy, genetic factors and ageing.

Periodontitis and COPD are also both characterised by neutrophilic tissue destruction suggesting a shared common pathway (ref). However, there remains some doubt of the strength of the relationship and its cause.

\section{Aim:}

To assess the self-reported dental habits and symptoms of oral disease in patients with COPD and AATD being reviewed in the stable clinical state when attending routine outpatient visits.

\section{Methods:}

Questionnaires were used to obtain self-reported data on dental habits and symptoms of dental disease from 188 patients with COPD and 142 patients with AATD attending for routine follow up appointments at Queen Elizabeth Hospital, Birmingham.

\section{Results:}

COPD patients were older (mean age 66+/- 10.2 years) than AATD patients ( $55+/-12.6$ years, $\mathrm{p}<0.01)$.

The COPD group brushed less frequently; $10 \%$ never brushing, $41 \%$ brushing once daily, 49\% twice daily compared to $0 \%, 29 \%$ and $71 \%$ respectively in the AATD group, $(\mathrm{p}<0.01)$.

Fewer of the COPD group routinely used dental floss ( $18 \%$ vs $43 \%, \mathrm{p}<0.01$ ) and visited their dentist less often (within 6months 39\% vs 75\%: within 12 months $17 \%$ vs $21 \%$ : within 24 months $13 \%$ vs $4 \%$ and never $31 \%$ vs $0 \%$, p<0.01).

The COPD cohort was significantly more likely to have had teeth extracted ( $30 \%$ vs $11 \%$ p < 0.01 ) but no significant differences were found in dental symptoms other than history of bleeding gums which was more 
prevalent in the AATD patients (48\% vs 25\%, p<0.01).

Conclusions: Patients with COPD had worse dental habits than patients with AATD.

AATD patients have better dental behaviours which may reflect a tendency to be more health aware and motivated. This may also partially explain the history of bleeding gums reflecting closer observation and/ or more frequent or excess brushing. Alternatively, COPD patients have a greater smoking history ( $97 \%$ current or ex-smokers vs 55\%) and nicotine can cause oral vasoconstriction thereby restricting local bleeding. Nevertheless the data supports previous observations of an association between COPD and periodontitis although the relationship may reflect features other than a common pathophysiological process.

\section{References:}

Usher, A.K. and R.A. Stockley, The link between chronic periodontitis and COPD: a common role for the neutrophil? BMC Med, 2013. 11: p. 241.

\section{The NIHR Translational Research Collaboration: The Relationship Between Ct Densitometry and Important Clinical Parameters in Alpha-1-Antitrypsin Deficiency (AATD)}

D. Crossley ${ }^{1}$ R.A. Stockley ${ }^{2}$

${ }^{1}$ Institute of Inflammation and Ageing, University of Birmingham, UK ${ }^{2}$ Lung Investigation Unit, University Hospitals Birmingham NHS Foundation Trust, UK

\section{Introduction:}

The NIHR rare diseases translational research collaboration was established as a network to facilitate research and clinical trials in rare diseases (figure 1). Birmingham acts as the coordinating centre and has lead the recruitment of 100 mild to moderate patients and 100 severe COPD patients unable to travel to the coordinating centre recruited mainly in Nottingham, London, Cambridge and Leicester. All patients undergo quantitative CT scanning, full lung function testing, extensive demographics plus blood and sputum sampling for biomarker analysis.

\section{Methods:}

To date 140 scans have been received and analysed by the percent of low attenuation voxels (LAA) at $-950 \mathrm{HU}$ and the 15th percentile using semi-automated software programme, Pulmo-CMS (Medis Medical Imaging, Leiden, Netherlands) and related this to data on FEV 1 and KCO, SGRQ and CAT score, uploaded to a central database to date. Lung density correlated with all lung function and quality of life measures (see examples below).

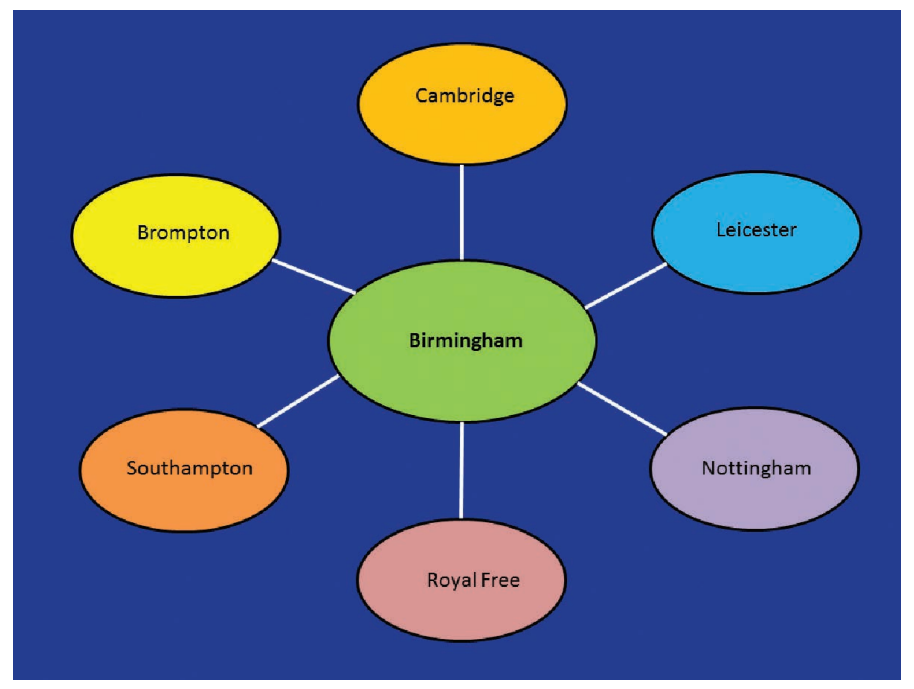

\section{Results:}

These results confirm that emphysema in AATD, is related to lung function, and conventional measures of health status. The consortium data analysis is ongoing.
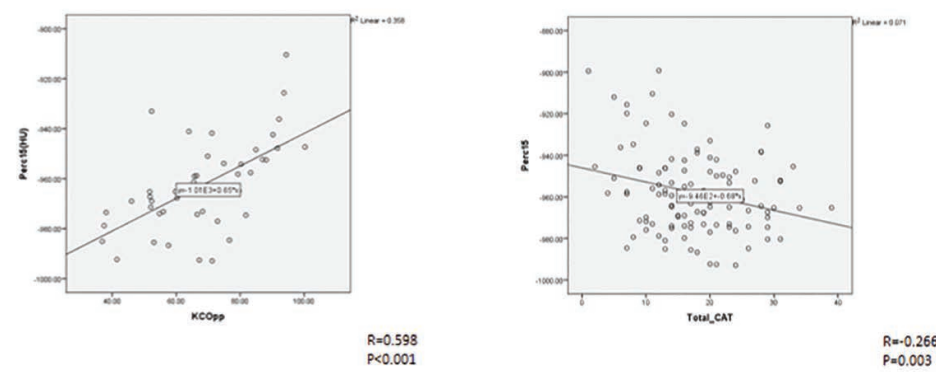


\section{The Changing Pattern of Presentation and Prognosis in UK AATD Patients}

A. Carnegy, S. Hughes, R.A.Stockley \& A.M. Turner

Institute of Inflammation and Ageing, University of Birmingham, UK

Lung Investigation Unit, University Hospitals Birmingham NHS Foundation Trust, UK

\section{Background:}

Alpha-1-Antitrypsin Deficiency (AATD) is a rare inherited condition that can cause Chronic Obstructive Pulmonary Disease (COPD). The National Registry for AATD (ADAPT Programme) has been running in Birmingham since 1996. This project aimed to assess differences in clinical phenotype at presentation, outcomes and treatment between patients enrolled at different times to the programme.

\section{Methods:}

Data from over 1000 patients with PiSZ and PiZZ AATD were extracted from ADAPT databases and augmented from medical records. Patients were split into groups based on when they first presented to the programme; this resulted in four groups, characterised by enrolment between 1996 and 2001, and subsequent five-year increments. Univariate and multivariate analyses were used to compare clinical features and treatment used for COPD at presentation between those in the first and last enrolled groups, as well as across all groups, and further addressed longitudinal outcomes such as mortality, lung function decline and exacerbation frequency.

\section{Results:}

Patients in later cohorts tended to be slightly older (median 52 v 49 years; p=0.03), have smoked less (median 13 v 20 pack years; p<0.001), have fewer exacerbations (median 0.9/year v 0.5/year; $\mathrm{p}<0.001$ ), be less breathless (MRC dyspnoea score 0: $23.3 \% \mathrm{v}$ $7.1 \%$; $<0.001$ ) and have a better quality of life (Median SGRQ 39.2 v 52.2; p<0.001). They also had better survival (Figure 1; $\mathrm{p}<0.001$ ). Over time the number of patients on LAMA and LABA/ICS increased (both $\mathrm{p}<0.001)$. Patients treated with these inhalers had fewer exacerbations in the multivariate analyses ( $p=0.05$ and $<0.001$ respectively). Lung function decline was inconsistent between cohorts but suggested that earlier cohorts were losing lung function more rapidly.

\section{Conclusion:}

This study suggests that AATD patients presenting to the programme now are healthier, which may reflect earlier diagnosis and better awareness of the condition. They are generally receiving aggressive COPD treatment and have better longitudinal outcomes compared to those presenting 20 years ago, though a causal effect of COPD treatment cannot be inferred.

Figure: Survival in the UK AATD cohort

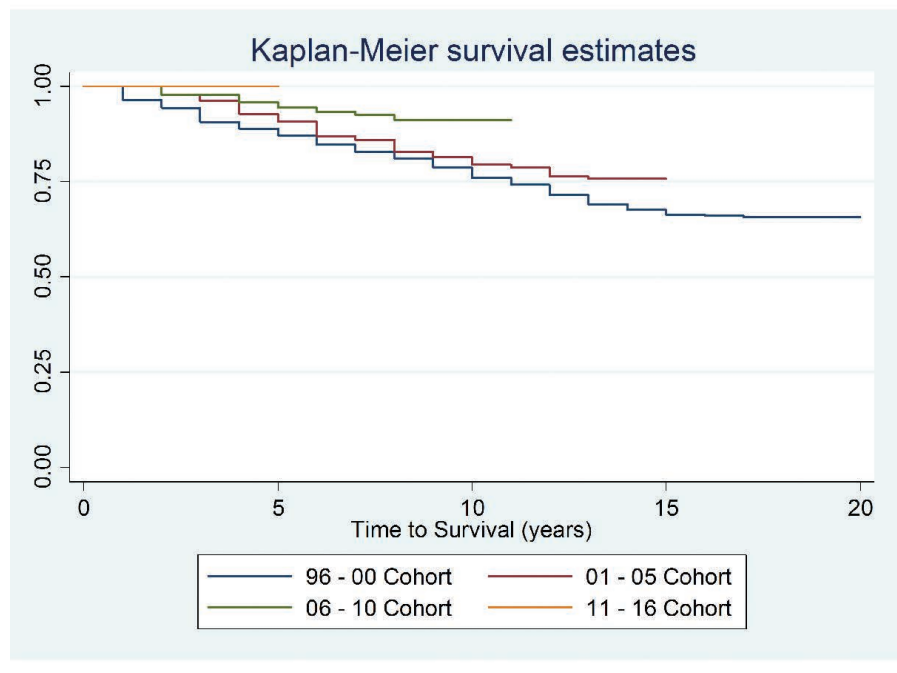

The figure shows cumulative survival in the group, with the $\mathrm{x}$ axis representing time from enrolment to survival analysis. The blue line represents the earliest enrolled patients, and the red line the most recently enrolled; difference between groups significant $(\mathrm{p}<0.001)$. 


\section{Adherence to Inhaled Medications Among High Grade Chronic Obstructive Pulmonary Disease (COPD) Patients}

\section{C.K.Rhee}

Division of Pulmonary, Allergy and Critical Care Medicine, Department of Internal Medicine, Seoul St Mary's Hospital, College of Medicine, The Catholic University of Korea, Seoul.

\section{Objective:}

To examine how adherence to inhaled medications among high-grade COPD patients affects healthcare utilization and costs.

\section{Data and Methods:}

A retrospective cohort study. We utilized a dataset from the Korean Health Insurance Review and Assessment Service (2008-2013) containing healthcare services information for 50 million beneficiaries. The study population is high-grade COPD patients. We defined "adherent" if a patient attains a Medication Possession Ratio (MPR) $\geq 80 \%$. We estimated effects of adherence on the use of ICUs and ERs using a multivariate logistic regression and, costs (all-cause and COPD-related) using a generalized linear model, by adjusting for patients' socio-demographic characteristics, health status and comorbidities.

\section{Results:}

Of 9,086 high-grade COPD patients, adherence declined from $34.7 \%$ to $22.3 \%$ over four years. Adherence was inversely associated with use of ICUs and costs and this was stronger as an adherent period elongated. The adherent group for four-year period had a lower likelihood of using ICUs (OR 0.74, CI 0.60-0.91) than the non-adherent group. Similarly, the adherent group for four-year period had a 10.4\% lower all-cause cost $(p<0.001)$ and an $11.7 \%$ lower COPD related cost $(p<0.0001)$ than its counterpart. However, this inverse association was not found with ERs.

\section{Conclusions:}

Adherence reduces healthcare utilization and costs among high-grade COPD patients and this implies adherence is not only clinically effective but also economically efficient. However, less than a quarter of them remained adherent for the four-year period, suggesting strategies are needed to improve adherence among this population.

\section{The Reference Values of the Scores Obtained from the Evaluating Respiratory Symptoms in COPD(E- Rs), Dyspnoea-12 (D-12) and the COPD Assessment Test (CAT) in a Working Population}

Koichi Nishimura ${ }^{1}$ Masaaki Kusunose ${ }^{1}$ Saya Nakamura ${ }^{1}$ Kazuyoshi Senda ${ }^{1}$ Kazuhito Nakayasu ${ }^{2}$ Satoshi Mitsuma ${ }^{3}$

${ }^{1}$ National Center for Geriatrics and Gerontology,-Obu, JAPAN ${ }^{2}$ Data Research Section, Kondo P.P. Inc., Osaka, JAPAN ${ }^{3}$ Niigata Association of Occupational Health Incorporated, Niigata, JAPAN

\section{Background:}

We previously reported that the COPD assessment test (CAT) score distribution overlapped remarkably in both healthy non-smoking subjects and in subjects with COPD. We aimed to investigate whether breathlessness by Dyspnoea-12 (D-12) or respiratory symptoms by the Evaluating Respiratory Symptoms in COPD (E-RS) could be related to the diagnosis of COPD.

\section{Purpose:}

To determine reference scores of the patient reported outcomes for healthy non-smoking subjects in a working population.

\section{Methods:}

A total of 1599 healthy industrial workers aged $\geq 40$ years performed spirometry and completed Japanese versions of the CAT, E-RS and D-12. Healthy nonsmoking subject was defined by $\mathrm{FEV}_{1}$ of $>85 \%, \mathrm{FEV}_{1} /$ FVC of $>0.7$ and smoking history of $<1$ pack-year that is identical to the ECLIPSE study. In order to determine reference values for each score, we calculated the 95th percentile of the scores in healthy, non-smoking subjects using the Monte Carlo method and used this as the upper limit of normal. In adition, 67 subjects with stable COPD were also studied at outpatient clinic. 


\section{Results:}

In 1599 subjects, a floor effect was seen in all of the scores, most marked with D-12.

\begin{tabular}{|l|l|l|l|}
\hline \multirow{2}{*}{} & \multicolumn{2}{|l|}{ In a Working Population. } & $\begin{array}{l}\text { At Outpatient } \\
\text { Clinic }\end{array}$ \\
\cline { 2 - 4 } & non-COPD & COPD & COPD \\
\cline { 2 - 4 } & FEV $_{1} /$ FVC $\geqq 0.7$ & FEV $_{1} /$ FVC $<0.7$ & FEV $_{1} / \mathrm{FVC}<0.7$ \\
\hline D-12 $(0-36)$ & $0.2 \pm 0.5$ & $0.3 \pm 0.8$ & $2.4 \pm 5.0$ \\
\hline CAT $(0-40)$ & $4.3 \pm 3.9$ & $4.8 \pm 4.1$ & $8.6 \pm 7.2$ \\
\hline E-RS $(0-16)$ & $1.2 \pm 1.9$ & $1.6 \pm 2.2$ & $6.0 \pm 6.5$ \\
\hline
\end{tabular}

From the data obtained from 646 healthy non-smoking subjects, the Bootstrap 95th percentile values were a E-RS Total score 4.44, indicating the reference value is $<5$. The reference value of the D-12 was calculated to be $<2$. For the CAT, it was $<11$.

\section{Conclusion:}

The reference value of the E-RS total, D-12 and CAT score is $<5,<2$ and $<11$ respectively.

\section{Quality of Life (QOL) Responder Rate Analysis Following Use of an Oscillating Positive Expiratory Pressure (OPEP) Device for Chronic Obstructive Pulmonary Disease (COPD): SGRQV CAT Assessments}

\section{J. Suggett}

Trudell Medical International, London, Ontario, Canada N5V $5 G 4$.

\section{Background:}

The Aerobika* OPEP device has been reported to improve quality of life outcomes for COPD patients with chronic bronchitis ${ }^{1,2}$. This abstract compares the responder rates from two separate studies using the same device, one with the St George's Respiratory Questionnaire (SGRQ) and the other with the COPD assessment test (CAT).

\section{Methods:}

Study 11, a randomized cross-over study in 27 COPD patients for 3-4 weeks, used the SGRQ. Study 22, a clinical assessment of 37 COPD patients over an 8-week period, used the CAT. Taking clinically significant measures of improvement of greater than 4 and at least 2 (for the SGRQ and CAT respectively), responder rates were calculated for the COPD patients with chronic bronchitis.

\section{Results:}

In study 1 , the mean SGRQ value for the 14 COPD patients with chronic bronchitis significantly improved from 49 to 40 ( $p=0.01$, paired t-test) following OPEP therapy. In study 2, the mean CAT value for the 26 COPD patients with chronic bronchitis significantly improved from 19.7 to 17.4 ( $\mathrm{p}=0.01$, paired $\mathrm{t}$-test) following OPEP therapy. In terms of responder rate analysis, using the recognized improvement thresholds noted above, $64 \%$ of the COPD patients with chronic bronchitis from study 1 showed a clinically significant improvement in Quality of Life compared to $62 \%$ from study 2 .

\section{Conclusions:}

The results from the two separate studies (using different validated QoL instruments) show good agreement, with nearly two thirds of COPD patients with chronic bronchitis exhibiting clinically significant improvements in Quality of Life following selfadministered treatment with the Aerobika* OPEP device.

\section{References:}

1. Svenningsen S, Paulin GA, Sheikh K, et al. Oscillatory Positive Expiratory Pressure in Chronic Obstructive Pulmonary Disease. COPD. 2015 Oct 2:1-9.

2. Suggett J. Review of Quality of Life outcomes following use of an Oscillating Positive Expiratory Pressure (OPEP) device for Chronic Obstructive Pulmonary Disease (COPD): 8 weeks field study using the COPD Assessment Test (CAT), ATS 2016 


\section{Cut-Off Points of the COPD Assessment Test for COPD Associated With Comorbidities: A Population-Based Study}

Manuela Karloh, Marcia M. M. Pizzichini, Emilio Pizzichini

Asthma and Airway Inflammation Research Center. Federal University of Santa Catarin, Brazil

\section{Background:}

The COPD Assessment Test (CAT) monitors health status in COPD. Although it is a disease-specific tool, it could also be influenced by comorbidities. A cut-off value of 10 has been suggested to identify patients with low and high scores.

\section{Aims:}

To determine the optimum cut-off points for the CAT score in COPD patients presenting with comorbidities.

\section{Method:}

Cross-sectional population-based study consisting of visits to households randomly selected. The CAT, a clinical questionnaire and spirometry were performed. Depression symptoms were assessed by the Hospital Anxiety and Depression Scale. The participants reported if they had heart diseases, rhinitis, and gastritis/reflux. The cut points were determined through the area under the curve (AUC) receiver operating characteristic curve, sensitivity and specificity. Statistical significance was taken as $\mathrm{p}<0.05$.

\section{Results:}

1057 subjects ( $58 \pm 11$ years, FEV1 $92.2 \pm 20.9 \%$ of predicted, CAT 6.9 \pm 7.0$)$, including $92 \mathrm{COPD}(65 \pm 11$ years, FEV1 $63.7 \pm 20.5 \%$ of predicted, CAT 10.6 \pm 8.8$)$ were evaluated. It was found a cut point of CAT $>15$ for COPD + depression symptoms (AUC 0.848, sensitivity 72.2, specificity 89.6,); CAT $>10$ for COPD + rhinitis (AUC 0.691, sensitivity 56.2, specificity 76.6); CAT $>9$ for COPD + gastritis/reflux (AUC 0.776, sensitivity 75.0, specificity 73.4); and CAT>8 for COPD + obesity (AUC 0.691, sensitivity 56.2, specificity 76.6) $(p<0.01$ for all).

\section{Conclusions:}

A CAT score $>15$ should be considered if the
COPD patient has depression symptoms. The other comorbidities evaluated did not interfere with cut-off point.

\section{Self-Management in Patients With COPD}

\author{
S. Pupyshev \\ Saint - Petersburg State University, Faculty of Medicine, \\ Saint-Petersburg, Russia
}

\section{Objective:}

To analyze effectiveness of over TV self-management programs(SMP) in to improve the quality of life (QOL) and course of the disease.

\section{Results:}

87 outpatients with COPD 2-3st (GOLD, 2014): visits to pulmonologist during last year - 2,7 $\pm 0,34$ times; visits to a GP- $2,3 \pm 0,28$; the number of hospitalizations due to exacerbations $-2,32 \pm 0,35$. Most of all visits to physician $(63,2 \%)$ were unscheduled and due to worsening of the disease. TV SMP was used during 12 months in 34 patients, which consisted of the electronic diary (the questionnaire EXACT-PRO), followed by SMP of the exacerbation based on symptoms assessment and using recommendations provided (treatment support program). Contact with medical staff was available. Compared with control group, which patients were followed in ordinary way, the number of exacerbations and hospitalizations in the study group decreased by $35 \%$ and $42 \%$, respectively, QOL improved in "activity" from $46,6 \pm 7,25$ to $31,7 \pm 3$,2 points, the "total number" - from $52,4 \pm 1,8$ to $37,0 \pm 1,6$ points.

\section{Conclusion:}

SMP is an integral part of modern, patient-centered biopsychosocial care. Future research should be aimed at full implementation of new technologies in daily medical practice. 


\section{Does Combined Respiratory and Palliative Care Management Improve Care for COPD Patients?}

\author{
A. Mulkerns ${ }^{1}$ P. O' Toole $^{1}$ P. Gregan ${ }^{2}$ T.J. McDonnell ${ }^{1}$ \\ ${ }^{1}$ Respiratory Department, St. Michaels Hospital, Dun \\ Laoghaire, Co. Dublin and St. Vincent's University \\ Hospital, Elm Park, Dublin 4. ${ }^{2}$ Palliative Care Service, \\ Blackrock Hospice, Blackrock, Co. Dublin.
}

\section{Introduction:}

COPD produces breathlessness, which is associated with frequent emergency department (ED) attendances. Palliative care aims to optimise quality of life by anticipating, preventing and treating suffering. This study aimed to evaluate if the joint management of a patient with advanced COPD between a respiratory and a specialist palliative care service influenced ED presentations, breathlessness and quality of life.

\section{Methods:}

Eleven patients with advanced COPD (mean FEV 1 $22.6 \% \pm 5.2$ ) were referred to the palliative care service when maximal therapy for COPD no longer provided symptom control. Treatment included input from the breathlessness intervention service, the day hospice and prescription of benzodiazepines and opioids as required. Patients also continued to be monitored and treated by the respiratory service.

\section{Results:}

The average number of ED presentations of the referred patients reduced significantly from $3.55 \pm 1.64$ in the six months prior to their referral to palliative care to $1.28 \pm 1.19$ in the six months after the referral $(p<0.05)$. There was also a significant improvement in their quality of life scores, with their average $\mathrm{mMRC}$ improving from $3.56 \pm 0.52$ to $2.8 \pm 0.6(p<0.05)$, and their average CAT reducing from $22.1 \pm 3.21$ to $18 \pm 3.51(\mathrm{p}<0.05)$.

\section{Conclusions:}

This data suggests that joint management of patients with advanced COPD between respiratory and palliative care service improves patient care.

\section{References:}

1. American Academy of Hospice and Palliative Medicine; Center to Advance Palliative Care; Hospice and Palliative Nurses Association; Last Acts Partnership; National Hospice and Palliative Care Organization.
National Consensus Project for Quality Palliative Care: clinical practice guidelines for quality palliative care, executive summary. $J$ Palliat Med. 2004;7(5):611-627.

2. Higginson, I. J., Bausewein, C., Reilly, C. C., Gao, W., Gysels, M., Dzingina, M., McCrone, P., Booth, S., Jolley, C. J. and Moxham, J. An Integrated Palliative and Respiratory Care service for patients with advanced disease and refractory breathlessness: A randomised controlled trial. The Lancet Respiratory Medicine 2014:2; 979-987.

\section{Prevalence of Sleep Apnoea and Its Associated Impact on Quality of Life in a Primary Care COPD Population}

Andy Dickens, Alexandra Enocson, Rachel Jordan, David Fitzmaurice, Peymane Adab

University of Birmingham, Birmingham, UK

\section{Introduction:}

COPD and obstructive sleep apnoea (OSA) are both associated with reduced quality of life. Previous studies estimate the prevalence of OSA among patients with moderate to severe COPD, but little is known about the impact on quality of life in a milder, primary care population.

\section{Aims \& objectives:}

To describe the characteristics of COPD patients stratified by sleep apnoea, and assess differences in quality of life in a primary care cohort.

\section{Methods:}

Data from the Birmingham COPD Cohort study was used to describe the proportion of COPD patients with OSA ('high risk' on the Berlin Questionnaire). An adjusted multivariable regression model was used to determine the association between OSA and CAT score.

\section{Results:}

The analysis sample $(\mathrm{n}=1037)$ had a mean age of 67.8 (range 42-96), median BMI of 27.5 (IQR 24.3, 31.4), mean $\mathrm{FEV}_{1} \%$ predicted of 60.8 (SD 18.2) and $76.2 \%$ were $\leq$ GOLD stage 2 . OSA was identified in $48.2 \%$ of the patients; these were younger and more likely to be obese and have a positive smoking history compared to those without OSA. Those with COPD and OSA reported higher CAT scores (mean difference 4.2, 95\% CI 3.03 to 5.30), signifying greater impact on their daily lives. 


\section{Conclusions:}

OSA is common amongst patients with COPD in primary care. COPD patients with OSA reported clinically worse quality of life, suggesting associations found in more severe COPD patients are also present in those managed within primary care.

\section{Prevalence and Characteristics of Low Oxygen Saturation (SPO2) in a Primary Care COPD Cohort}

Alexandra Enocson, Rachel Jordan, Peymane Adab, Andy Dickens, David Fitzmaurice,

University of Birmingham, Birmingham, UK

\section{Introduction:}

Long-term oxygen therapy (LTOT) reduces mortality and improves function in COPD patients. Guidelines for oxygen therapy vary; however, all agree that LTOT be evaluated in patients at risk of hypoxemia.

\section{Aims and objectives:}

To describe prevalence of low $\mathrm{SpO}_{2}$ at rest, post-exercise and self-reported LTOT use amongst primary care COPD patients.

\section{Methods:}

Baseline data ( $\mathrm{n}=1558$ ) from the Birmingham COPD Cohort study were used to describe clinical and demographic characteristics by $\mathrm{SpO}_{2}$ level. "Low $\mathrm{SpO}_{2}$ " was defined as $\leq 92 \%$ at rest. We also reported $\geq 4 \%$ $\mathrm{SpO}_{2}$ drop post-exercise.

\section{Results:}

159 (11\%) patients had $\leq 92 \%$ resting $\mathrm{SpO}_{2}$. Patients with low $\mathrm{SpO}_{2}$ were more likely to be ever-smokers $(p<0.05)$, obese $(p<0.05)$ with worse dyspnoea $(p<0.001)$ and lower exercise capacity $(\mathrm{p}=0.015)$. Hospitalisation and exacerbation rates did not differ by $\mathrm{SpO}_{2}$ level. All models were adjusted for age, sex, pack-years and GOLD stage.

After exercise, 92 (8\%) desaturated $>4 \%$, from their resting $\mathrm{SpO}_{2}$; the majority of whom 64 (70\%) had normal $\mathrm{SpO}_{2}$ at baseline. Only 20 (13\%) patients with low $\mathrm{SpO}_{2}$ at rest reported LTOT.

\section{Conclusion:}

Primary Care COPD patients with lower $\mathrm{SpO}_{2}$ were more likely to be obese, ever-smokers and more breathless. $87 \%$ of these patients were not receiving LTOT but may benefit.

\section{Delivering High Quality Spirometry in Primary Care: A Report of Spirometry Quality in the Birmingham Lung Improvement Studies (BLISS) Programme}

Shamil Haroon, Andy Dickens, Martin Miller, Brendan Cooper, Alexandra Enocson, Rachel Jordan, David Fitzmaurice and Peymane Adab

University of Birmingham, Birmingham, UK

\section{Introduction:}

The Birmingham Lung Improvement Studies (BLISS) programme delivered spirometry in general practices in the West Midlands, UK as part of a large cluster RCT of COPD case finding and a large COPD cohort study. We report the quality of the spirometry delivered through this large research programme.

\section{Methods:}

Post-bronchodilator spirometry was delivered in primary care using ndd EasyOne spirometers and bespoke software (developed by $\mathrm{MM}$ ) by research assistants trained to ARTP standards but with no prior experience of lung function testing. All spirometry measures were quality checked by a lung function specialist (MM). Measures of quality included repeatability and acceptability.

\section{Results:}

Data from 33,533 blows from 3,975 subjects from 71 general practices were analysed. Only $0.8 \%$ of patients had unusable data. $88 \%$ of $\mathrm{FEV}_{1}$ and $74 \%$ of $\mathrm{FVC}$ measures were repeatable within $150 \mathrm{mls}$, $91 \%$ of blows had acceptable starts and $60 \%$ of blows achieved an end of test plateau of $<25 \mathrm{mls}$.

\section{Conclusion:}

The BLISS programme was able to achieve high quality spirometry in primary care using technicians with no prior experience of lung function testing. This could be 
used as a model for delivering high quality spirometry in primary care.

\section{Preoperative Predictors of Improvement With Lung Volume Reduction Surgery}

B.A. Whippo, $\mathrm{MSN}^{1}$ P.A. Jellen, $\mathrm{MSN}^{1}$ B.M. Thomashow, $\mathrm{MD}^{1}$ M.E. Ginsburg, $\mathrm{MD}^{2}$ C. Chiuzan, $\mathrm{PhD}, \mathrm{MD}^{3}$ W.A. Bulman, $\mathrm{MD}^{2}$

${ }^{1}$ New York Presbyterian Hospital, New York, NY, ${ }^{2}$ Columbia University Medical Center, New York, NY, ${ }^{3}$ Department of Biostatistics, Columbia University, New York, NY

\section{Objective:}

The objective of this study was to determine whether there were any pre-operative values that predicted spirometric and quality of life improvement after LVRS.

\section{Methods:}

Retrospective analysis was performed on 101 subjects who had LVRS. Testing/ patient selection was performed according to CMS guidelines. All patients had upper lobe predominant emphysema on CT. Clinically meaningful outcomes were: $\geq 100 \mathrm{ml}$ increase in $\mathrm{FEV}_{1}$ and $\geq 5$ points decrease in the UCSD score at 6 months and 1 year relative to baseline. Several pre-operative values were identified a priori as possible predictors of success: age, maximum watts, $\mathrm{DLCO}, \mathrm{pO}_{2}, \mathrm{RV}$, TLC, 6-minute walk distance and BMI.

\section{Results:}

Improvement in $\mathrm{FEV}_{1}$ was seen in $80 \%$ patients at 6 months and in $73 \%$ patients at 1 year. Improvement in quality of life was noted in 93\% patients at 6 months and in $83 \%$ patients at 1 year. A BMI greater than 21 was predictive of improvement in FEV 1 at 6 months and 1 year, with an Odds Ratio of OR=7.35 (95\% CI: 2.0526.39) and $O R=5.26$ (95\% CI: 1.44-19.23), respectively. Mortality was $0 \%$ at 6 months.

\section{Conclusion:}

Only BMI > 21 was associated with $\mathrm{FEV}_{1}$ improvement. None of the other variables analyzed showed any clinically significant predictability.

\section{4-Hour Lung Function Profile of Novel Co-Suspension ${ }^{\mathrm{TM}}$ Technology Glycopyrronium/Formoterol Metered Dose Inhaler Versus Placebo and Tiotropium (Spiriva ${ }^{\circledR}$ Respimat ${ }^{\circledR}$ ), in Patients with Moderate-to- Very-Severe Chronic Obstructive Pulmonary Disease}

Colin Reisner ${ }^{1}$ Gregory Gottschlich ${ }^{2}$ Faisal Fakih ${ }^{3}$ Andras Koser ${ }^{4}$ Luis Delacruz ${ }^{5}$ Samir Arora ${ }^{6}$ Gregory J Feldman ${ }^{7}$ Krishna Pudi ${ }^{8}$ Shahid Siddiqui ${ }^{9}$ Chad Orevillo ${ }^{1}$ Andrea Maes ${ }^{1}$

${ }_{1}^{1}$ Pearl Therapeutics Inc., Morristown, NJ, USA, ${ }^{2} \mathrm{New}$ Horizons Clinical Research, Cincinnati, OH, USA ${ }^{3}$ Florida Pulmonary Research Institute, Winter Park, FL, USA, ${ }^{4}$ Palmetto Medical Research Associates, Easley, SC, USA, ${ }^{5}$ Greenville Pharmaceutical Research, Greenville, SC, USA, ${ }^{6}$ Aventiv Research, Columbus, OH, USA ${ }^{7}$ S. Carolina Pharmaceutical Research, Spartanburg, SC, USA, ${ }^{8}$ Upstate Pharmaceutical Research, Greenville, SC, USA, ${ }^{9}$ AstraZeneca, Gaithersburg, MD, USA, (former employee of Pearl Therapeutics Inc.)

\section{Introduction:}

GFF MDI is a fixed-dose combination of glycopyrronium (GP) $14.4 \mu \mathrm{g}$ (equivalent to glycopyrrolate $18 \mu \mathrm{g}$ ) and formoterol fumarate (FF) 9.6 $\mathrm{g}$, delivered by a metered dose inhaler (MDI) using novel Co-Suspension ${ }^{\mathrm{TM}}$ Technology. We evaluated the 24-hour lung function profile of GFF MDI versus placebo and open-label tiotropium (Soft Mist $^{\mathrm{TM}}$ Inhaler [SMI]; Spiriva ${ }^{\circledR}$ Respimat $^{\circledR}$ ) in patients with moderate-to-very-severe COPD.

\section{Methods:}

In this Phase IIIb, multicentre, randomized, double-blind, three-period crossover trial (NCT02347072), patients received 28 days of twice-daily GFF MDI 14.4/9.6 $\mathrm{gg}$, placebo MDI and once-daily open-label tiotropium SMI $5 \mu \mathrm{g}$. The primary endpoint was normalized and baseline-adjusted FEV 1 AUC0-24 on Day 29.

\section{Results:}

80 patients received at least one dose of treatment and 75 were included in the modified intent-to-treat population. GFF MDI showed a least squares mean (LSM) difference versus placebo MDI (265 mL; p<0.0001) and open-label 
tiotropium SMI (80 mL; p=0.0001) for FEV 1 AUC0-24 on Day 29. GFF MDI LSM difference from placebo MDI in $\mathrm{FEV}_{1}$ AUC on Day 29 was similar for hours 12-24 and 0-12 (277 and $251 \mathrm{~mL}$, respectively); GFF MDI LSM difference versus open-label tiotropium SMI was greater during hours $12-24(120 \mathrm{~mL} ; \mathrm{p}<0.0001)$ than 0-12 (48 mL; $\mathrm{p}=0.0325$ ).

\section{Conclusions:}

GFF MDI improved 24-hour lung function versus placebo MDI in moderate-to-very-severe COPD, with a consistent benefit following morning and evening dosing. The improvement versus open-label tiotropium SMI was larger in the second, than first, 12 hours of dosing. These results support twice-daily dosing of GFF MDI.

\section{Long-Term Safety and Efficacy of GFF MDI: A LAMA/LABA Fixed-Dose Combination of Glycopyrronium/ Formoterol 14.4/9.6 mg Delivered by an MDI Using Novel Co-Suspension ${ }^{\mathrm{TM}}$ Technology: Results of a 1-Year Extension Study in Patients With COPD (PINNACLE-3)}

Nicola A. Hanania ${ }^{1}$ Donald P. Tashkin ${ }^{2}$ Edward M. Kerwin $^{3}$ James F. Donohue ${ }^{4}$ Michael Denenberg ${ }^{5}$ Denis $O^{\prime}$ Donnell ${ }^{6}$ Dean Quinn ${ }^{7}$ Shahid Siddiqui ${ }^{8}$ Chad Orevillo ${ }^{9}$ Andrea Maes ${ }^{9}$ Colin Reisner ${ }^{9}$

${ }^{1}$ Baylor College of Medicine, Houston, TX, USA, ${ }^{2}$ David Geffen School of Medicine at UCLA, Los Angeles, CA, USA, ${ }^{3}$ Clinical Research Institute of Southern Oregon, Medford, OR, USA, ${ }^{4}$ University of North Carolina School of Medicine, Chapel Hill, NC, USA, ${ }^{5}$ Clinical Research of Rock Hill, Rock Hill, SC, USA, 'Queen's University, Kingston, ON, Canada, ${ }^{7}$ P3 Research Ltd, Wellington, New Zealand ${ }^{8}$ AstraZeneca, Gaithersburg, MD, USA, (former employee of Pearl Therapeutics Inc.), ${ }^{9}$ Pearl Therapeutics Inc., Morristown, NJ, USA

\section{Introduction:}

GFF MDI is a fixed-dose combination of glycopyrronium

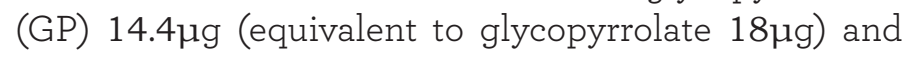
formoterol fumarate (FF) 9.6 $\mathrm{g}$, delivered by a metered dose inhaler (MDI) using novel Co-Suspension ${ }^{\mathrm{TM}}$
Technology. PINNACLE-3 (NCT01970878) was a 28-week extension of two Phase III, randomized, placebo-controlled, 24-week trials (PINNACLE-1 and PINNACLE-2), which evaluated the long-term safety and efficacy of GFF MDI versus its monocomponent MDIs over the duration of 52 weeks.

\section{Methods:}

A randomly selected proportion of patients completing 24 weeks' treatment in PINNACLE- 1 and -2 continued GFF MDI, FF MDI or GP MDI twice daily, or open-label tiotropium $18 \mu \mathrm{g}$ dry powder inhaler once daily, for a further 28 weeks. Placebo recipients were not included in PINNACLE-3. The primary objective of this oneyear extension study was to evaluate the long-term safety of active treatments without a long-term placebo component. The primary efficacy endpoint evaluated the effect of GFF MDI versus its monocomponents on lung function (forced expiratory volume in 1 second $\left.\left[\mathrm{FEV}_{1}\right]\right)$.

\section{Results:}

Of 3274 patients who received active treatment in PINNACLE-1 and PINNACLE-2, 893 continued the same treatment in PINNACLE-3 (GFF MDI = 290; FF MDI = 213; GP MDI = 219; open-label tiotropium = 171). There were no unexpected safety findings. Across 52 weeks' treatment, the overall incidence of adverse events (AEs) was similar for GFF MDI (64.6\%), FF MDI (60.4\%), GP MDI (59.9\%) and open-label tiotropium (69.2\%). The most frequent AEs with GFF MDI (nasopharyngitis 6.8\%, cough $4.2 \%$ and upper respiratory tract infection $3.8 \%$ ) were comparable with the monocomponents and open-label tiotropium.

For changes from baseline in trough $\mathrm{FEV}_{1}$ and peak FEV 1 within 2 hours post-dose across 52 weeks' treatment, GFF MDI demonstrated significant improvement versus FF MDI (65 and $88 \mathrm{~mL}$, respectively), GP MDI (57 and $129 \mathrm{~mL}$, respectively) and open-label tiotropium (25 mL and $93 \mathrm{~mL}$, respectively). GFF MDI also demonstrated significant improvement versus GP MDI ( $<<0.0001)$ and open-label tiotropium $(p=0.0002)$ for average daily use of rescue medication, and numerical improvement versus FF MDI ( $\mathrm{p}=0.0750)$. Numeric trends for improvement with GFF MDI versus individual monocomponents were seen for St George's Respiratory Questionnaire (SGRQ) total score. 


\section{Conclusions:}

PINNACLE-3 demonstrates long-term safety and tolerability, and consistent and sustained efficacy, of GFF MDI versus its monocomponents in patients with moderate-to-very-severe COPD over 52 weeks of treatment.

\section{Indacaterol/Glycopyrronium Versus Salmeterol/Fluticasone in the Flame Study: Risk for Suppression of Hypothalamic Pituitary-Adrenal Axis Function and Oral Candidiasis in Moderate-To- Very Severe Patients}

Jadwiga A. Wedzicha ${ }^{1}$ Karen Mezzi ${ }^{2}$ Petter Olsson ${ }^{3}$ Robert Fogel ${ }^{4}$ Chau Thach ${ }^{4}$ Donald Banerji ${ }^{4}$

${ }^{1}$ National Heart and Lung Institute at Imperial College, London, United Kingdom; ${ }^{2}$ Novartis Pharma AG, Basel, Switzerland; ${ }^{3}$ Novartis Sverige AB, Stockholm, Sweden; ${ }^{4}$ Novartis Pharmaceuticals Corporation, East Hanover, NJ, United States

\section{Introduction:}

GOLD recommends LABA/ICS or LAMA as first-line treatment in COPD patients at high risk of exacerbations. However, ICS use is associated with pneumonia, hypothalamic pituitary-adrenal (HPA) axis suppression, and oral candidiasis. We report FLAME study results regarding $\mathrm{HPA}$-axis function, pneumonia, and risk of oral candidiasis with indacaterol/glycopyrronium (IND/GLY) versus salmeterol/fluticasone (SFC).

\section{Methods:}

FLAME was a 52-week, randomised, double-blind

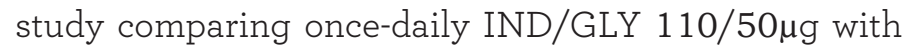
twice-daily SFC 50/500 $\mu$ g in patients with moderateto-very severe COPD, and $\geq 1$ exacerbation in previous year. HPA-axis function was assessed by measuring 24-hour urine cortisol/creatinine ratio. Pneumonia was confirmed by radiographic imaging and oral candidiasis by culture-positive swabs.

\section{Results:}

Of 3362 randomised patients, 535 were in a urine cortisol subset. Pneumonia rate was lower with IND/ GLY versus SFC (3.2\% versus 4.8\%; $\mathrm{p}=0.017$ ). IND/GLY significantly delayed time-to-first pneumonia $(\mathrm{p}=0.011)$ and lowered severe pneumonia rate versus SFC $(1.8 \%$ versus $2.6 \%$ ). Median percentage change from baseline in 24-hour urinary cortisol/creatinine ratio at Week 52 was $5.62 \%$ (IND/GLY) versus $-10.39 \%$ (SFC); $\mathrm{p}=0.018$. Oral candidiasis rate was lower with IND/GLY (1.2\% versus $4.2 \%$; $p<0.001$ ).

\section{Conclusion:}

The systemic effects of SFC were demonstrated by a significant effect on HPA axis function. Risk of pneumonia and oral candidiasis was also lower with IND/GLY.

\section{Once-Daily Indacaterol/ Glycopyrronium (IND/GLY) Reduces the Rate of Moderate or Severe Exacerbations Compared With Twice-Daily Salmeterol/Fluticasone (SFC) in COPD Patients at Risk of Exacerbations: The Flame Study}

Jadwiga A. Wedzicha ${ }^{1}$ Karen Mezzi ${ }^{2}$ Michael Larbig ${ }^{2}$ Robert Fogel ${ }^{3}$ Chau Thach $^{3}$ Francesco Patalano ${ }^{2}$ Donald Banerji ${ }^{3}$

${ }^{1}$ National Heart and Lung Institute, Imperial College London, London, UK; ${ }^{2}$ Novartis Pharma AG, Basel, Switzerland; ${ }^{3}$ Novartis Pharmaceuticals Corporation, East Hanover, NJ, USA

\section{Introduction:}

The FLAME study showed superiority of IND/GLY in reducing the risk of exacerbations versus SFC in COPD patients with a high risk of exacerbation (Wedzicha et al. N Eng J Med. 2016). We present results regarding reduction in rate of moderate or severe exacerbations with IND/GLY versus SFC from this study.

\section{Methods:}

In this 52-week multicentre double-blind study, patients $\geq 40$ years with moderate-to-very severe COPD and history of $\geq 1$ exacerbation in the previous year were

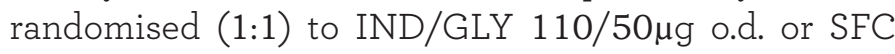
$50 / 500 \mu$ g b.i.d.

\section{Results:}

IND/GLY reduced the annual rate of moderate or severe 
exacerbations by $17 \%$ with a significant $21 \%$ reduction in exacerbations requiring treatment with antibiotics and a significant $20 \%$ reduction in exacerbations requiring treatment with both systemic corticosteroids and antibiotics, compared with SFC. Number of COPD exacerbation requiring systemic corticosteroids only was comparable between IND/GLY and SFC. The rate of hospitalisations was lower in IND/GLY versus SFC (Table).

\section{Conclusion:}

IND/GLY significantly reduced the rate of moderate or severe exacerbations, exacerbations requiring treatment with antibiotics alone, and exacerbations requiring both systemic corticosteroids and antibiotics, compared with SFC.

\section{Table:}

Rate of moderate or severe COPD exacerbations during the treatment period

Table: Rate of moderate or severe COPD exacerbations during the treatment period

\begin{tabular}{|c|c|c|c|c|}
\hline \multirow[b]{2}{*}{$\begin{array}{l}\text { Moderate or severe COPD } \\
\text { exacerbations }\end{array}$} & \multicolumn{2}{|c|}{$\begin{array}{l}\text { Total Number of } \\
\text { Exacerbations } \\
\text { n (\%)* }\end{array}$} & \multirow[b]{2}{*}{$\begin{array}{l}\text { Ratio of rates } \\
(\mathbf{9 5 \%} \mathrm{CI})\end{array}$} & \multirow[b]{2}{*}{ p value } \\
\hline & $\begin{array}{l}\text { IND/GLY } \\
(\mathrm{N}=1651)\end{array}$ & $\begin{array}{l}\mathrm{SFC} \\
(\mathrm{N}=1656)\end{array}$ & & \\
\hline Overall & $1265(100 \%)$ & $1452(100 \%)$ & $0.83(0.75,0.91)$ & $<0.001$ \\
\hline $\begin{array}{l}\text { Requiring treatment with systemic } \\
\text { corticosteroids only }\end{array}$ & $281(22.2 \%)$ & $266(18.3 \%)$ & $0.99(0.80,1.22)$ & 0.896 \\
\hline $\begin{array}{l}\text { Requiring treatment with antibiotics } \\
\text { only }\end{array}$ & $369(29.2 \%)$ & $453(31.2 \%)$ & $0.79(0.67,0.93)$ & 0.004 \\
\hline $\begin{array}{l}\text { Requiring treatment with systemic } \\
\text { corticosteroids and antibiotics }\end{array}$ & $610(48.2 \%)$ & $728(50.1 \%)$ & $0.80(0.70,0.91)$ & $<0.001$ \\
\hline Requiring hospitalization & $209(16.5 \%)$ & $241(16.6 \%)$ & $0.87(0.69,1.09)$ & 0.231 \\
\hline
\end{tabular}

\section{Indacaterol/Glycopyrronium (IND/GLY) Reduces the Risk of Exacerbations Versus Salmeterol/ Fluticasone (SFC) in Moderate- To-Very Severe COPD Patients Irrespective of Prior ICS/LABA/ LAMA Therapy: The Flame Study}

Jadwiga A. Wedzicha ${ }^{1}$ Karen Mezzi ${ }^{2}$ R. Timothy Ayers ${ }^{3}$ Chau Thach ${ }^{3}$ Robert Fogel ${ }^{3}$ Francesco Patalano ${ }^{2}$ Donald Banerji ${ }^{3}$

${ }^{1}$ National Heart and Lung Institute at Imperial College, London, United Kingdom; ${ }^{2}$ Novartis Pharma AG, Basel, Switzerland; ${ }^{3}$ Novartis Pharmaceuticals Corporation, East Hanover, NJ, United States

\section{Introduction:}

GOLD strategy recommends LABA/ICS combination, and/ or a LAMA as the first-line treatment, and ICS/ LABA/LAMA triple therapy as an alternative choice for COPD patients with high risk of exacerbations. FLAME was the first study to show superiority of IND/GLY (LABA/LAMA) in reducing risk of exacerbations vs. SFC (LABA/ICS) in patients with history of exacerbations. We report the reduction in risk of COPD exacerbations with IND/GLY vs. SFC in patients with or without prior triple therapy.

\section{Methods:}

FLAME, a 52-week, randomised, double-blind study compared once-daily IND/GLY $110 / 50 \mu \mathrm{g}$ vs. twicedaily SFC 50/500 $\mathrm{ug}$ in patients with moderate-to-very severe COPD with $\geq 1$ moderate/severe exacerbation in previous year. In this post-hoc analysis, time to first COPD exacerbation (mild, moderate or severe) and moderate/severe COPD exacerbation with IND/GLY vs. SFC were analysed.

\section{Results:}

Of 3354 patients included in this analysis, 1148 (34.1\%) were on prior triple therapy. In patients with prior triple therapy, IND/GLY showed a significant $14 \%$ and $21 \%$ risk reduction in any exacerbation and moderate/severe exacerbation, respectively vs. SFC (table). In patients without prior triple therapy, reductions were $16 \%$ and $23 \%$ (table). 


\section{Conclusion:}

IND/GLY significantly reduces risk of exacerbations versus SFC, irrespective of prior triple therapy in exacerbating patients with moderate-to-very severe COPD.

\section{Table:}

Time to first (mild, moderate or severe) COPD exacerbation and moderate/severe COPD exacerbation with IND/GLY versus SFC

\begin{tabular}{lcc}
\hline Subgroup & Hazard ratio $(95 \%$ confidence interval) & p-value \\
\hline \begin{tabular}{l} 
With prior ICS/LABA/LAMA therapy $(\mathrm{n}=1148)$ \\
\hline $\begin{array}{l}\text { Any (mild, moderate or } \\
\text { severe) COPD exacerbation }\end{array}$
\end{tabular} & $0.86(0.76,0.98)$ & 0.026 \\
$\begin{array}{l}\text { Moderate/severe COPD } \\
\text { exacerbation }\end{array}$ & $0.79(0.68,0.93)$ & 0.004 \\
\hline \begin{tabular}{l} 
Without prior ICS/LABA/LAMA therapy $(\mathrm{n}=2206)$ \\
\hline $\begin{array}{l}\text { Any (mild, moderate or } \\
\text { severe) COPD exacerbation }\end{array}$
\end{tabular} & $0.84(0.76,0.92)$ & $<0.001$ \\
$\begin{array}{l}\text { Moderate/severe COPD } \\
\text { exacerbation }\end{array}$ & $0.77(0.68,0.88)$ & $<0.001$ \\
\hline
\end{tabular}

COPD, chronic obstructive pulmonary disease; ICS, inhaled corticosteroid; LABA, long-acting $\beta 2$-agonist; LAMA, longacting muscarinic antagonist

\section{Indacaterol/Glycopyrronium (IND/ GLY) Showed Consistent Superiority to Salmeterol/Fluticasone (SFC) for Lung Function Outcomes: The Flame Study}

Nicolas Roche ${ }^{1}$ Michael Larbig ${ }^{2}$ Karen Mezzi ${ }^{2}$ Chau Thach $^{3}$ Robert Fogel ${ }^{3}$ Francesco Patalano ${ }^{2}$ Donald Banerji ${ }^{3}$

${ }^{1}$ Service de Pneumologie AP-HP, University Paris Descartes (EA 2511), Paris, France; ${ }^{2}$ Novartis Pharma AG, Basel, Switzerland; ${ }^{3}$ Novartis Pharmaceuticals Corporation, East Hanover, NJ, United States

\section{Introduction:}

LABA/ICS and/or LAMA are recommended treatments in COPD patients at high risk of exacerbations. The FLAME study was the first to demonstrate superiority of IND/GLY (LABA/LAMA) over SFC (LABA/ICS) in COPD patients with history of exacerbations. We present results regarding effect of IND/GLY vs. SFC on lung function from this study.

\section{Methods:}

This 52-week double-blind study randomised (1:1) patients (with history of $\geq 1$ exacerbation in the past year and with a post-bronchodilator $\mathrm{FEV}_{1}$ predicted $\geq 25 \%$ to $<60 \%$ ) to once-daily IND/GLY $110 / 50 \mu \mathrm{g}$

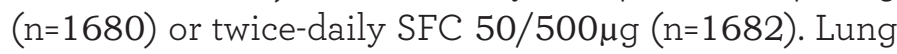
function was assessed using trough spirometry and in a subset of patients using serial spirometry after day 1 (FEV ${ }_{1}$ AUCO-12h) and after 4, 12, 26, 38, and 52 weeks of treatment ( $F E V_{1}, F V C$ and $\left.\mathrm{FEV}_{1} \mathrm{AUC}_{0-12 \mathrm{~h}}\right)$.

\section{Results:}

Of the 3362 randomised patients, $82.2 \%$ completed 52 weeks of treatment. IND/GLY resulted in significant $(\mathrm{p}<0.001)$ improvements in pre-dose trough $\mathrm{FEV}_{1}$, $\mathrm{FEV}_{1} \mathrm{AUC}_{0-12 \mathrm{~h}}$ and trough FVC vs. SFC over 52 -week treatment period (Table).

Table: Lung function improvement from baseline with IND/GLY vs. SFC over 52-week treatment period

\begin{tabular}{|c|c|c|c|c|c|c|}
\hline & \multicolumn{6}{|c|}{ LSM treatment difference $(95 \% \mathrm{CI})$} \\
\hline & Day 1 & Week 4 & Week 12 & Week 26 & Week 38 & Week 52 \\
\hline $\begin{array}{l}\text { Pre-dose } \\
\text { trough } \mathrm{FEV}_{1} \text {, } \\
\mathrm{mL}\end{array}$ & NA & $\begin{array}{l}73(0.061, \\
0.085)\end{array}$ & $\begin{array}{l}78 \\
(0.066 \\
0.091)\end{array}$ & $\begin{array}{l}86(0.073, \\
0.100)\end{array}$ & $\begin{array}{l}73(0.059 \\
0.087)\end{array}$ & $\begin{array}{l}62(0.048 \\
0.077)\end{array}$ \\
\hline $\begin{array}{l}\mathrm{FEV}_{1} \mathrm{AUC}_{0-} \\
12 \mathrm{~h}, \mathrm{~mL}\end{array}$ & $\begin{array}{l}27 \\
(0.004, \\
0.050)^{*}\end{array}$ & $\begin{array}{l}101(0.071, \\
0.131)\end{array}$ & $\begin{array}{l}117 \\
(0.085, \\
0.149)\end{array}$ & $\begin{array}{l}116 \\
(0.084, \\
0.148)\end{array}$ & $\begin{array}{l}113(0.080 \text {, } \\
0.146)\end{array}$ & $\begin{array}{l}110(0.074, \\
0.145)\end{array}$ \\
\hline $\begin{array}{l}\text { Pre-dose } \\
\text { trough FVC, } \\
\mathrm{mL}\end{array}$ & NA & $\begin{array}{l}177(0.155, \\
0.199)\end{array}$ & $\begin{array}{l}206 \\
(0.182, \\
0.229)\end{array}$ & $\begin{array}{l}209 \\
(0.184, \\
0.235)\end{array}$ & $\begin{array}{l}183(0.157, \\
0.209)\end{array}$ & $\begin{array}{l}160(0.133, \\
0.187)\end{array}$ \\
\hline
\end{tabular}

All treatment differences are statistically significant (all;

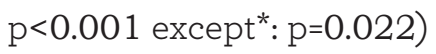

AUC, area under curve; CI, confidence interval; FEV 1 , Forced expiratory volume in 1 second; FVC, forced vital capacity; LSM, least squares mean; NA, not applicable

\section{Conclusions:}

IND/GLY demonstrated consistently superior improvements over SFC in lung function throughout the 52 -week treatment period. These data provide additional evidence on the role of IND/GLY as first line treatment in COPD patients at a high risk of exacerbations. 


\section{Pharmacist Intervention in Chronic Obstructive Pulmonary Disease With Support of a Medicines Use Plan (PICMEUP)}

Andrew Evans, Lucy Wheeler, Kerenza Hood, Rebecca Playle, Darrell Baker, Fiona Walker, Sioned Davies.

Cardiff University, UK

\section{Background:}

Pharmacist-led educational programmes on selfmanagement increase Chronic Obstructive Pulmonary Disease (COPD) patients' medication adherence and decrease emergency hospital admissions. Community pharmacists are commissioned by the NHS to provide a Medicines Use Review (MUR) service, however this service could be optimised to increase health-related quality of life and decrease health service contacts in patients with COPD.

\section{Method:}

This randomised controlled feasibility study examined the feasibility of introducing a personalised medicine use plan at discharge, followed by a community based Medicine Use Review 6 weeks later, on patients with an acute exacerbation of COPD.

\section{Main result:}

139 patients were eligible for the study, 75 were excluded (54\%), with 19 refusing to participate. Complete data were available for $52 \%$ of the recruited participants. The intervention showed no difference in health-related quality of life, hospital readmission rates, or patient enablement at 3-months post intervention.

\section{Conclusions:}

The majority of participants were willing to be recruited and randomised. However, the 24-hour requirement for consent may have removed those patients who were stabilised and discharged quickly, thus arguably the group most likely to benefit from intervention. The results from this preliminary study will help refine the methodology to enable the success of a larger trial.

Table 1: Health related quality of life scores in intervention and control groups

\begin{tabular}{|l|l|l|l|l|l|l|}
\hline & \multicolumn{2}{|l|}{ Intervention } & \multicolumn{2}{l|}{ Control } & Intervention effect & p-value \\
& $\mathrm{n}$ & Mean (SD) & $\mathrm{n}$ & Mean (SD) & and $\%$ CI & \\
\hline${ }^{\text {ISGRQ QOL }}$ & 25 & $63.9(9.3)$ & 25 & $63.2(13.3)$ & $0.8(-5.8$ to 7.3$)$ & 0.816 \\
${ }^{2}$ SGRQ QOL & 17 & $62.9(10.5)$ & 15 & $61.6(13.7)$ & $1.2(-7.5$ to 10.0$)$ & 0.778 \\
\hline
\end{tabular}

${ }^{1}$ ITT analysis with imputed data

${ }^{2}$ Complete case analysis

Table 2: Intention to treat analyses for the primary outcome

\begin{tabular}{|l|l|l|l|l|l|l|}
\hline & \multicolumn{2}{|l|}{ MUR } & \multicolumn{2}{l|}{ No MUR } & \multirow{2}{*}{ Effect and 95\% CI } & p-value \\
\cline { 1 - 5 } & $\mathrm{n}$ & Mean (SD) & $\mathrm{n}$ & Mean (SD) & & \\
\hline SGRQ QOL & 18 & $61.5(2.4)$ & 32 & $64.8(2.1)$ & $-3.2(-10.0$ to 3.5) & 0.341 \\
\hline
\end{tabular}

